\title{
Evaluation of surface wind fields for prediction of directional ocean wave spectra during Hurricane Sandy
}

\author{
Vanessa C. C. Bennett ${ }^{\mathrm{a}}$, Ryan P. Mulligan ${ }^{\mathrm{a}, *}$ \\ ${ }^{a}$ Department of Civil Engineering, Queen's University, Kingston, ON, Canada
}

\begin{abstract}
Hurricane Sandy was the largest storm on historical record in the Atlantic Ocean basin with extensive coastal damage caused by large waves and high storm surge. In this study, three different spatially-varying surface wind and atmospheric pressure fields that are used for forecasting or hindcasting hurricane waves on the continental shelf are investigated. These wind fields include two 2D parametric wind models (Holland model, H80; Generalized Asymmetric Holland Model, GAHM), and a 3D atmospheric model with data assimilation (WeatherFlow Regional Atmospheric Modelling System, WRAMS). These wind fields are used to drive wave hindcasts using coupled Delft3DSWAN hydrodynamic and ocean wave models on a regional grid, and the bulk wave statistics and the directional wave spectra are compared to observations at offshore wave buoys to investigate the impact of differences between the complex wind fields on predictions of the sea surface evolution.

The spatial and temporal distribution of bulk wave parameters are different for each wind field. The WRAMS wind field produces wave model predictions in the best agreement with significant wave height observations, followed by the GAHM and H80 wind fields, with mean correlation coefficients of $0.91,0.82$ and 0.75 , respectively averaged
\end{abstract}

\footnotetext{
*Corresponding Author: Ryan P. Mulligan

Email address: mulligar@queensu.ca (Ryan P. Mulligan)
} 
over 9 sites. The directional wave spectra for Hurricane Sandy was bi-modal predominantly in the two left quadrants of the hurricane, in agreement with buoy observations. The results indicate that a regional atmospheric wind model that has the best description of the wind field is the most appropriate forcing for hindcasting hurricane waves when detailed observations are available. However a parametric vortex model that incorporates wind at multiple isotachs results in very good agreement with wave observations when used in the wave model, and is a useful too for forecasting hurricane sea surface conditions. The results of this study are relevant for other tropical cyclones that undergo extratropical transition or are influenced by other atmospheric disturbances at mid-latitudes, resulting in storms with large spatial size and high asymmetry. Keywords: hurricane winds, ocean surface waves, directional wave spectra, spectral wave model, SWAN

\section{1. Introduction}

2 Hurricanes, also known as tropical cyclones, are some of the worlds most powerful and 3 destructive weather events with strong winds that create large waves and high storm ${ }_{4}$ surges that can flood coastal areas and cause shoreline erosion. These storms are the 5 costliest natural disasters in the USA (Emanuel, 2005), and have been increasing in 6 frequency and intensity over the last 30 years due to climate change. Associated with 7 climate change, an increase in average storm intensity is expected which will increase \& damage to coastal regions (Emanuel, 2005). Global climate model predictions indi9 cate an increase in frequency of $2-11 \%$ by 2100 of the most intense tropical cyclones ${ }_{10}$ (Knutson et al., 2010). Goldenberg et al. (2001) describes the observed doubling of the 1 number of cyclones since 1995 in the Atlantic basin and suggests that the changes are 12 caused by higher sea surface temperatures and the lower vertical wind shear. A better ${ }_{3}$ understanding of tropical cyclone winds is needed to improve prediction of impacts and 
mitigation of damage from the increasing intensity of these storms. Numerical modelling of ocean wave and water level conditions is an important method of forecasting costly and hazardous marine conditions from storms like hurricanes.

Atmospheric wind models combined with ocean circulation and wave models are powerful tools to predict and better understand hurricane conditions. As an example, hurricane waves are currently forecast using the Wavewatch III spectral wave model (Tolman, 2009) by the U.S. National Weather Service (2016) where real-time predictions of hurricane wave conditions are computed every 3 hours on a coarse grid with a resolution of $0.25^{\circ}$ (approximately $28 \mathrm{~km}$ ). Hurricane waves are also commonly hindcast using Wavewatch III, the Simulating Waves Nearshore (SWAN) model (Booij et al., 1999), the Wave Model (WAM) or the steady-state spectral wave (STWAVE) model (Jensen et al., 2016). Huang et al. (2013) used SWAN to test the sensitivity of wind drag coefficients under hurricane conditions on deep water waves, and determined that the default wind input settings are suitable for hurricanes and produce reliable predictions in shallow water. Hu and Chen (2011) used SWAN to study wave spectra for hurricane events in the Gulf of Mexico to obtain insight into the controls on the shape of bi-modal wave spectra under complex hurricane winds. Mori (2012) also used SWAN to simulate the waves under typhoon conditions near the Japan coast, to investigate the occurrence of freak waves due to nonlinear fourwave interactions in the different quadrants. Chen and Curcic (2015) used a coupled atmosphere-wave-ocean model for Hurricanes Ike (2008) and Sandy (2012) to better understand the spatial distribution of integrated mean wave properties and the directional spectra.

Wave models coupled with hydrodynamic models are also used to predict the combined surface waves and storm surge. For example, Sebastian et al. (2014) used SWAN coupled with the Advanced Circulation model (ADCIRC), to study how hurricanes drive storm surge in Galveston Bay. Dietrich et al. (2011) validated ADCIRC coupled 
with the unstructured mesh version of SWAN for Hurricanes Katrina (2005) and Rita (2005). The Delft3D hydrodynamic model (Lesser et al., 2004) coupled to SWAN has been used to investigate the estuarine response to hurricane storm surge and surface waves in a shallow estuary (Mulligan et al., 2015). Several of these studies use the parametric wind vortex model described by Holland (1980) to simulate the hurricane wind field needed to force the hydrodynamic and wave models. In the present study the goal is to simulate the ocean wave spectra generated by a hurricane wind field, while in related work the coupled wave model circulation models are used to predict storm surge and barrier island overwash (Bennett et al., 2017).

The focus of the present study is to investigate a strong storm event that generated large surface waves in the coastal ocean, and had different wind characteristics than typical storms that have been used to develop parametric hurricane wind models. The SWAN spectral wave model is used to simulate Hurricane Sandy over a regional model grid covering the western continental shelf of the Atlantic Ocean for the central United States (Figure 1). Three different spatially-varying surface wind fields are evaluated and compared to wind observations, including the parametric Holland model (H80), a parametric Generalized Asymmetric Holland Model (GAHM), and results from the WeatherFlow Regional Atmospheric Modelling System (WRAMS). These winds are used to drive the spectral wave model, and the wave statistics and directional wave spectra are compared to observations at offshore wave buoys to investigate the impact of differences between the complex wind fields on predictions of the sea surface evolution. It is hypothesized that the WRAMS wind field should produce the best agreement with wave observations since this wind input has been developed using a 3D atmospheric model that assimilates wind observations, where H80 and GAHM wind fields have been developed from 2D parametric hurricane wind models. The influence of these different wind fields on the generation of surface waves are investigated for Hurricane Sandy because it was different in size and meteorological characteristics from typical north 
Atlantic hurricanes.

\section{The Wind Field During Hurricane Sandy}

Hurricane Sandy formed in the southwestern Caribbean Sea (Blake et al., 2013) and gained strength as it travelled northeast, parallel to the southeast United States coastline (Figure 1). The hurricane made a westward turn that is uncharacteristic of typical tropical hurricane tracks (714 year chance of perpendicular landfall, Hall and Sobel (2013)) and made landfall as a Category 1 hurricane on the Saffir-Simpson scale. Sandy is also considered a hybrid "superstorm" due to the combination of tropical and nontropical characteristics as it approached the coast (Halverson and Rabenhorst, 2013), since it acquired dual energy sources in the mid-Atlantic Ocean from warm tropical waters (typical of a hurricane) and extratropical sources such as the cooler jet stream trough in the middle and upper atmosphere (typical of a Nor'easter). Landfall occurred just northeast of Atlantic City (AC), NJ, on October 29, 2012 at 2330 UTC (Coordinated Universal Time), equivalent to Yearday 303.98 (where Yearday 1 is defined as January 1, 2012) with $36 \mathrm{~ms}^{-1}$ maximum sustained surface winds that caused a high storm surge along the coast of NJ and NY. The storm was nearly $2,000 \mathrm{~km}$ in diameter with a radius to maximum wind speed up to $330 \mathrm{~km}$ near landfall, and is described as the largest storm on historical record in the Atlantic Ocean and the second costliest hurricane to hit the United States since 1900 (Blake et al., 2013) after Hurricane Katrina (2005). Accurately simulating the Hurricane Sandy surface wind field is important in predicting the ocean scale storm wave and surge properties that led to extensive coastal damage. For this study, the wind field for Hurricane Sandy was developed from three different wind models including H80, GAHM and WRAMS to simulate the wind and pressure fields at a $10 \mathrm{~m}$ elevation above mean sea level. 


\subsection{Holland (1980) Model (H80)}

The Holland (1980) model, is an analytical model of the radial profiles of sea level pressure and wind velocity components in a tropical cyclone. This model uses hyperbolic pressure profiles that are scaled and used in the gradient wind equations to define the hurricane wind profile and the radius to maximum winds $\left(R_{\max }\right)$. The model requires the "Best Track" parameters of the hurricane including the eye latitude, eye longitude, $R_{\max }$, wind speed $U$ at $R_{\max }$, the minimum central atmospheric pressure $\left(P_{\min }\right)$, the ambient atmospheric pressure, and the ambient wind conditions. This wind model has been successfully used in several studies to force hydrodynamic and wave models to predict waves and storm surges (e.g. Mulligan et al., 2015; Hu and Chen, 2011) during cyclonic storms.

The H80 wind model was implemented in MATLAB and used to generate winds for Hurricane Sandy over a 3.5 day period from Oct. 28 at 0000 UTC to Oct. 31 at 1200 UTC (Yearday 302.0-303.5) on a spherical grid with $18 \mathrm{~km}$ horizontal resolution and 1-hour temporal resolution. The Best Track wind parameters were obtained every 6 hours from Landsea et al. (2016) and used to produce the wind field as indicated in Figure 2a-b for two time steps corresponding to Yearday 303.3 (Oct. 29 at 0500) and Yearday 303.9 (Oct. 29 at 2000). To achieve storm asymmetry, the forward moving velocity $\left(V_{f m}\right)$ is calculated from the average 6-hour storm speed and added to the gradient wind velocity.

\subsection{Generalized Asymmetric Holland Model (GAHM)}

The GAHM model was adapted from the H80 model by Gao et al. (2013) by better taking into account the asymmetry of a hurricane. It differs from H80 with modifications that include eliminating the assumption of cyclostrophic balance at $R_{\max }$ and using multiple storm isotachs (e.g. wind speeds at several radii from the storm centre) 
from National Hurricane Center (NHC) wind forecast advisories. These modifications allow GAHM to generate a more accurate representation of the wind field for a wider range of hurricanes, and ensure that the predicted winds match all available isotach information. In contrast, the Holland model uses only the highest isotach at $R_{\text {max }}$ while GAHM uses the radial distance to the 34, 50 and 64 knot isotachs. Gao et al. (2013) shows that GAHM is a better representation of 7 historical storms when compared with NHC's best track information.

In the present study, the Hurricane Sandy wind field is generated from GAHM and is interpolated onto a grid at $18 \mathrm{~km}$ horizontal resolution and 1 hour temporal resolution. The wind field is shown in Figure 2c-d at two different time steps corresponding to Yearday 303.3 and 303.9 and is typically stronger over a larger area and more symmetric than the wind field produced by H80.

\subsection{WeatherFlow Regional Atmospheric Modelling System (WRAMS)}

The Regional Atmospheric Modelling System (RAMS) (Pielke et al., 1992; Cotton et al., 2003) is a 3D nonhydrostatic mesoscale meteorological modelling system with equations for time dependent changes in velocity, pressure and cloud and ice microphysics. WeatherFlow has implemented the RAMS model (WRAMS) as an operational model on specific domains at high resolution (WeatherFlow, 2016). WRAMS is used to simulate Hurricane Sandy by assimilating observational data from meteorological stations along the east coast of the United States. Data assimilation in RAMS (Federico, 2013) uses observations from WeatherFlow's mesoscale observing network (HURRNET) of over 130 meteorological stations designed to withstand hurricane conditions. This data set uses the temporal evolution of 1-minute sustained winds, 3-second gusts and atmospheric pressure recorded at 10 meters above ground level. The wind field has been used in a previous study of Hurricane Sandy to investigate inundation in New York City using a finite element storm surge model (Wang et al., 2014). The WRAMS Hurricane 
Sandy hindcast was computed on a regional grid of North America with 33 vertical layers and a horizontal resolution of $18 \mathrm{~km}$. In the present study the surface wind and atmospheric pressure fields are extracted at 1-hourly temporal resolution over the region indicated in Figure 1. The wind field is shown in Figure 2e-f at two different time steps corresponding to Yearday 303.3 and 303.9, indicating that the storm size was significantly larger than predicted by the H80 and GAHM parametric wind models, with higher spatial variability.

\subsection{Comparison of Wind Fields}

The surface wind fields generated using the H80 model show a significantly stronger east side of the hurricane track and a much weaker west side with similar intensity on the north and south sides. The GAHM wind field is similar to the H80 but less asymmetric in shape and has a more significant decrease in wind speed in the eye of the hurricane. The most intense part of the hurricane is generally on the east side of the track, but changes from the southeast to the northeast as the storm moves northward and changes direction. The WRAMS wind field is the most representative of the actual winds during Hurricane Sandy, as it includes assimilated observations and a full physics-based set of equations to describe the atmospheric conditions. This is indicated in Figure 2 by the large region of high winds and the bands of different wind speeds within the hurricane. This model also includes the influence of land on the storm indicated by the significant decrease in wind speed as the storm moves over the continent (Figure 2f).

The predicted wind components and atmospheric pressures are compared to the observed data at six observation locations (Table 1) in Figure 3. H80 has the lowest agreement with observed wind components $(U, V)$ but is in better agreement with the observed atmospheric pressure $(P)$ in comparison to GAHM. GAHM indicates relatively good predictions of the wind components but has weaker agreement with 
atmospheric pressure observations. WRAMS has the highest agreement with all observations for $U, V$, and $P$, indicating that this wind field is likely the best forcing for wave and storm surge models.

\section{Methods}

\subsection{Model Description}

Delft3D-Wave is the SWAN model (Booij et al., 1999) that is coupled with the Delft3DFlow hydrodynamic model (Lesser et al., 2004). SWAN is a third generation, phaseaveraged wave model that uses the action balance equation to predict the evolution of the wave action density spectrum $(N)$ in space and time. The action balance equation is given by:

$$
\frac{\partial N}{\partial t}+\frac{\partial c_{x} N}{\partial x}+\frac{\partial c_{y} N}{\partial y}+\frac{\partial c_{\sigma} N}{\partial \sigma}+\frac{\partial c_{\theta} N}{\partial \theta}=\frac{S_{t o t}}{\sigma}
$$

where the left side represents the change in wave action $(N)$ over time $(t)$ and the propagation of the wave action in geographical space (phase speeds are $c_{x}$ and $c_{y}$ in $x$ and $y$ space, respectively), the shifting of the relative frequency $(\sigma)$ due to variations in depths and currents, and directional changes $(\theta)$ caused by depth- and current-induced refraction (turning rate $\left.c_{\theta}\right)$. The right side of the equation $\left(S_{t o t}\right)$ represents processes that generate, dissipate or redistribute spectral wave energy (Zijlema, 2010)

$$
S_{t o t}=S_{i n}+S_{w c}+S_{n l 4}+S_{b o t}+S_{b r k}+S_{n l 3}
$$

where $S_{i n}$ is the transfer of wind energy to waves, $S_{w c}$ is the dissipation of wave energy due to whitecapping, $S_{n l 4}$ is the nonlinear transfer of wave energy due to quadruplet interaction, $S_{b o t}$ is the dissipation due to bottom friction, $S_{b r k}$ is the dissipation due to wave breaking and $S_{n l 3}$ is the nonlinear triad interaction.

Delft3D-Flow is a hydrodynamic model (Lesser et al., 2004) used for predicting 
currents and water levels that solves the unsteady shallow water equations derived from the Reynolds averaged Navier Stokes equations for an incompressible free surface flow. The system of equations includes the horizontal momentum equations, continuity equation, transport equation and a turbulence closure model.

\subsection{Model Setup}

The model was implemented on an orthogonal curvilinear grid in a two-dimensional (2D) spherical coordinate system extending from $30.5^{\circ} \mathrm{N}$ to $42.0^{\circ} \mathrm{N}$ and from $-81.5^{\circ} \mathrm{E}$ to $-66.0^{\circ} \mathrm{E}$ with a spatial resolution of $2.7 \mathrm{~km}$. This resolution was determined to be ideal in resolving the ocean wave characteristics, and yielded results that were no different from models with coarser $(5.4 \mathrm{~km})$ or finer $(1.8 \mathrm{~km}$ and $0.5 \mathrm{~km})$ grids. The domain spans approximately 1,280 km N-S and 1,440 km E-W has open flow boundaries on the east and south sides. The bathymetry was obtained from the ETOPO1 (1 arc minute resolution) global relief model (Amante and Eakins, 2009) which has a horizontal resolution of approximately $1.8 \mathrm{~km}$. The depth-averaged Delft3D-Flow model is applied on the same orthogonal curvilinear grid as SWAN to simulate the barotopic storm surge that influences the wave field. The model runs were initialized with a water level of $z$ $=0.0 \mathrm{~m}$ and model parameters include fluid density of $\rho=1025 \mathrm{kgm}^{-3}$, the default Chezy bottom friction coefficient of $C_{z}=65$ applied uniformly and the default horizontal eddy viscosity of $A_{H}=1 \mathrm{~m}^{2} \mathrm{~s}^{-1}$. The present study focusses on ocean waves generated by the hurricane wind field, however the wave and circulation models are coupled to simulate the effect of the storm surge on the waves and for consistency with a study by Bennett et al. (2017) where storm surge is investigated in detail.

The spectral resolution in SWAN was configured with 49 frequency bins over a range of $0.05-3.00 \mathrm{~Hz}$ and directional bins of $10^{\circ}$. SWAN operates in 3rd generation mode with a default bottom friction of $C_{J}=0.067 \mathrm{~m}^{2} \mathrm{~s}^{-3}$ parameterized using the JONSWAP formulation (Hasselmann et al., 1973). Depth-induced breaking 
in shallow water uses a dissipation coefficient $\alpha=1.00$ and a breaking parameter $\gamma=0.73$ (Battjes and Janssen, 1978). Whitecapping was modelled based on the van der Westhuysen et al. (2007) formulation, quadruplet interactions are based on the Discrete Interaction Approximation (Hasselmann et al., 1985) and all other parameters in SWAN are default values. Tests were conducted to investigate the sensitivity of the spatial grid resolution, the bottom roughness coefficient, and triad wave-wave interactions, with model results indicating negligible differences.

After sensitivity tests using default wind drag coefficients produced results that did not match observations, the drag coefficients were modified for hurricane conditions. The wind drag coefficient is defined as a function of wind speed and values of $C_{d}=0.0020,0.0025$ and 0.0040 were used for wind speeds of $U<20 \mathrm{~ms}^{-1}, 20$ $30 \mathrm{~ms}^{-1}$ and $>30 \mathrm{~ms}^{-1}$ respectively. These drag coefficients were selected from the results of Fan and Rogers (2016) who investigated the relationship between $C_{d}$ and wave spectra for Hurricane Ivan (2004), based on the data and simulations presented in Fan et al. (2009) for wind speeds up to $75 \mathrm{~ms}^{-1}$. This is consistent with the work of Holthuijsen et al. (2012) (in which a considerable reduction in drag coefficients for $U>40 \mathrm{~ms}^{-1}$ is defined) since the winds in Hurricane Sandy were $U \leq 36 \mathrm{~ms}^{-1}$.

The model was run for a 3.5 day period from Oct. 280000 UTC to Oct. 311200 UTC (Yearday 302.0 and 305.5) with forcing prescribed hourly by the wind components and atmospheric pressure fields over the model domain. During this time Hurricane Sandy propagated from the southern boundary of the model domain, followed a northeastward track, turned northwestward, became extratropical at $38.8^{\circ} \mathrm{N}$ latitude and dissipated over land. The model time step is 1-minute and coupling between SWAN and Delft3DFlow occurs every 60 minutes. The model is used to simulate three cases, corresponding to the surface wind and pressure generated from the three hurricane wind models. 


\subsection{Observations}

Due to the large size and high intensity of Hurricane Sandy, many weather stations on the mid-Atlantic coast were damaged or failed to measure throughout the storm. Six stations listed in Table 1 were able to capture the wind and pressure time series and were used to calibrate the wind models including 4 NOAA buoys (National Oceanic and Atmospheric Or 2016) at Nantucket (NT), New York Harbour (NYH), Long Island (LI) and Delaware Bay (DB) and 2 land-based weather stations at the Field Research Facility (FRF) in Duck NC, and Chesapeake Light (CL) shown in Figure 1. Data from 9 NOAA wave buoys listed in Table 1 are compared to the wave model results, including the 4 abovementioned buoys and 5 others at Block Island (BI), Cape Henry (CH), Virginia Beach (VB), Oregon Inlet (OI) and East Hatteras (EH).

\section{Results}

The H80, GAHM and WRAMS hurricane wind and atmospheric pressure fields are each used as input to the models in separate simulations. The bulk wave statistics including the significant wave height $\left(H_{s}\right)$, mean absolute wave period $\left(T_{m 01}\right)$, and peak direction $\left(\theta_{P}\right)$, and the wave spectra are compared to observations to determine the influence of each wind field on the ocean conditions.

\subsection{Wave Statistics}

The significant wave height for each wind field is shown in Figure 4 at the same times as the winds shown in Figure 2, and follow a similar cyclonic pattern. H80 produced the largest wave heights on the east side of the track just north of the strongest winds, with smaller waves on the southwest side of the hurricane south of the weakest winds. The GAHM wind field generated waves in a similar pattern with the largest waves north of the strongest winds in the southeast quadrant of the storm. The WRAMS wind field 
generated waves a similar spatial distribution to the winds with slightly smaller wave heights that cover a larger area.

The predicted significant wave height is compared to the observed significant wave height at 9 buoys shown in Figure 5, with the largest $H_{s}$ of over $10 \mathrm{~m}$ typically on the east side of the track at NYH, LI, BI, and NT. The model performance is assessed by calculating four statistics: the correlation coefficient $(\mathrm{R})$, the root-mean-squared error (RMSE), the bias and the scatter index (SI) for the bulk wave characteristics $\left(H_{s}, T_{m 01}, \theta_{P}\right)$. The RMSE is given by

$$
R M S E=\left[\frac{1}{N_{p}} \sum_{i}\left(x_{i}-y_{i}\right)^{2}\right]^{\frac{1}{2}},
$$

where $x_{i}$ are observations, $y_{i}$ are model predictions and $N_{p}$ is the total number of points. The bias is the mean difference between the observations and the model results:

$$
\text { Bias }=\frac{1}{N_{p}} \sum_{i}\left(x_{i}-y_{i}\right),
$$

and the scatter index is

$$
S I=\frac{R M S E}{\left[\frac{1}{N_{p}}\left(\sum_{i} x_{i} \sum_{i} y_{i}\right)\right]^{\frac{1}{2}}}
$$

The statistical results for the simulated significant wave height are presented in Table 2 for each wind field. The H80 winds produced waves with the lowest agreement with observations with R ranging from $0.33(\mathrm{NT})$ to $0.90(\mathrm{CH})$ as indicated in Figure 6 with an average $\bar{R}=0.75$ for all 9 sites (Table 2). Waves simulated using winds from GAHM indicate higher correlation with observations data with a range of $\mathrm{R}$ from 0.62 (DB) to 0.96 (BI) with an average $\bar{R}=0.82$ for all 9 sites. Waves produced using the WRAMS wind field have the highest correlation with observations with a range of $\mathrm{R}$ from $0.77(\mathrm{NT})$ to $0.98(\mathrm{CH})$ with an average $\bar{R}=0.91$.

The model results for the mean absolute wave period and peak wave direction are 
compared with observations in Figure 7 and Figure 8. Similar to the significant wave height shown in Figure 5, the WRAMS and GAHM wind fields are in better agreement with measurements than the $\mathrm{H} 80$ wind field at most sites. The mean absolute wave period time series is similar to the significant wave height time series, with the longest wave periods up to 13 s observed during the strongest parts of the storm. In Figure 8 a large change in the peak wave direction for the observations and wind fields is shown on Yearday 303.1 at EH and Yearday 303.9 at $\mathrm{CH}$ as the hurricane passes by and the wave direction shifts from $0^{\circ}$ to $360^{\circ}$. The peak direction observations often vary greatly over a short period of time and shift between values, caused by the difference in spectral peaks from the local wind-generated waves and from swell that propagate in different directions at different frequencies.

\subsection{Wave Spectra}

The 1-dimensional (1D) wave spectra and the 2-dimensional (2D) directional wave spectra are presented in Figures 9-11 at selected buoys. Evolution of the wave energy density at Virginia Beach (VB) and Long Island (LI) throughout the storm indicate that the spectral observations (Figure 9a,c) are similar to model results produced using the WRAMS wind field (Figure 9b,d). Higher energy lower frequency swell $(f=0.05-$ $0.10 \mathrm{~Hz}$ ) is observed during the storm, arriving first at VB since it is further south than LI. Higher frequency wind sea $(f>0.1 \mathrm{~Hz})$ is a major component of the spectra especially at VB, since offshore hurricane winds (e.g. Figure 2f) primarily generate waves after passage of the eye of the storm (Yearday 303.5-304.5). The model results generated using the WRAMS wind field slightly under-predict the wave energy, and the duration of the storm compared to the observations.

The simulated 1D wave spectra for each wind field is compared to observations at four buoy locations in Figure 10 for three time steps indicated in Figure 9. The predictions indicate good general agreement with the observations, however the simulations 
do not to capture the same magnitude of local wind-generated wave and swell peaks as observed by the buoys. The GAHM wind field produces very good agreement with the observations but tends to over predict the wave energy, consistent with the significant wave height data (Figure 5). In particular, the large increase in wave energy in Figure 10k is correlated with the large increase in wave height in Figure $5 \mathrm{~g}$ at VB on Yearday 303.9. The H80 and the WRAMS wind fields produce very similar waves with lower correlation with $H_{s}$ observations but with a better agreement in spectral shape, with bi-modal spectra at DB and VB (Figure 10e-h) driven by onshore hurricane swell and offshore wind sea.

The 2D directional wave spectra for observations and SWAN results using the WRAMS wind field are shown in Figure 11 at 3 locations. The WRAMS wind field produces directional spectra that are similar to observations in frequency and direction, but the predicted energy distribution is narrower and smoother than the observations. This suggests that the model predicts the peaks in directional spectra well, but misses the minor spectral components likely associated with local wind fluctuations resulting from the complex and chaotic sea surface under the hurricane.

\section{Discussion}

\subsection{Influence of Wind Field on Waves}

The three surface wind fields are different in size and shape. They each have a different spatial wind distribution with the highest wind speeds in different regions relative to the hurricane eye (Figure 2). This results in different spectral energy levels in different areas of the storm indicated by the significant wave height (Figure 4), e.g. to the east (H80), south (GAHM), and southeast/northeast (WRAMS) of the storm centre on

Yearday 303.3. The time series indicate general agreement with the maximum value of $H_{S}$ produced using all three wind fields (Figure 5), however the data-model agreement 
is poor at buoys located furthest east (e.g. EH, BI, NT), particularly after the hurricane has passed. This is likely due to other swell events coming in from the greater Atlantic Ocean that are not simulated by the model, since the waves in the model are generated only by winds over the regional domain. The GAHM wind field produces significant wave height results that consistently over-predict the $H_{s}$ observations with RMSE of $1.3 \mathrm{~m}$ particularly after the peak of the storm has passed the buoys located close to the coast (NYH, LI, CH, DB, VB, OI) shown in Figure 5. The WRAMS and H80 wind fields consistently result in under-prediction of the $H_{s}$ with RMSE of $1.33 \mathrm{~m}$ and 2.44 m.

The right side of the hurricane typically has wave spectra that is uni-modal with higher energy closer to the storm centre (e.g. LI and NYH, Figure 10). The left side of the storm typically has bi-modal spectra (e.g. DB and VB, Figure 10) and is not always accurately predicted using these wind fields. The WRAMS wind field results in wave spectra that has good agreement with the shape of the observed spectra but does not produce the same energy magnitude. This is evident from the generally underpredicted significant wave height, the shorter duration of high frequency waves through the storm (Figure 9), and the distribution of the directional spectra (Figure 11). The GAHM wind field results in better agreement with the magnitude of the frequency spectra but not the same spectral shape compared to the observations (Figure 10). The H80 winds consistently under-predict the intensity of the hurricane and results in significant wave height and wave spectra that are not as accurate as those generated by GAHM or WRAMS.

\subsection{Directional Spectra of Hurricane Waves}

Many hurricanes produce wind fields that are well-described using simple parametric wind models. For tropical cyclones close to the coast of Australia, Young (2006) observed that spectra in most quadrants are dominated by swell generated near the 
intense wind crescent of the hurricane at some earlier point in the storm and is mixed with the local wind-sea, resulting in a directionally skewed spectrum. Hurricane Sandy was different from typical tropical hurricanes in terms of its large size (Figure 12a), combination of tropical and no-tropical storm characteristics, and westward turn in track. However we observe the wave spectra in each quadrant during Hurricane Sandy is similar to tropical cyclones studied by others, suggesting that the dominant spectral features developed as a result of the hurricane characteristics of this superstorm.

The present results are compared to the $\mathrm{Hu}$ and Chen (2011) classification of hurricane wave spectra to investigate the difference compared to other events. $\mathrm{Hu}$ and Chen (2011) suggest that hurricane generated spectra are typically uni-modal, with some bimodal spectra in specific geographic regions relative to the eye of the hurricane. To investigate this, the Hurricane Sandy directional spectra predicted using the WRAMS wind field is analyzed by dividing the storm into four quadrants (Q1-Q4) relative to north with the eye in the centre, where Q1 is the northeast quadrant and the other quadrants follow sequentially counter-clockwise as shown in Figure 12b. Even though the storm track was directed to the northwest at this time, the classification of quadrants relative to north is applied here since a significant component of the forward moving velocity is directed northward and the region of maximum wind speed and largest significant wave height is located east of the eye.

The simulated wave spectra are shown in Figure 12c-f, and are generally consistent with $\mathrm{Hu}$ and Chen (2011), indicating energy in the right-side (east, Q1, Q4) quadrants that is higher than in the left-side (west, Q2, Q3) quadrants due to asymmetry of the wind field. The results also show agreement that spectra in the two right quadrants are dominated by higher frequency waves, particularly in Q3. The highest $H_{s}$ of up to $12 \mathrm{~m}$ occur in Q1 and Q4, and are swell-dominated with lower frequency wave energy.

Hu and Chen (2011) report that bi-modal spectra most prominently occur in Q2Q3, and define four types of bi-modal hurricane spectra where: Type I is a large 
distance $\left(>6 R_{\max }\right)$ from the hurricane centre; Type II has a large difference between wind and wave directions; Type III has sea and swell components from the same direction, and Type IV occurs due to shallow water coastal effects. The present model results indicate that Hurricane Sandy has bi-modal wave spectra, that are mainly Types II and III. Type II (Figure 10g-l) occurs at DB and VB that are located in Q2-Q3. The fetch-limitation by the coast is particularly evident on the shelf at VB, and combined with the distance from the storm centre this results in sea and swell from different directions (Figure 11c,f). LI and NYH are in Q2-Q1 and are dominated by uni-modal spectra. Compared to observations, the model results using WRAMS predicts the Type II bi-modal spectra at some locations and times (Figure 10g,h,j), however it does not always simulate two spectral peaks (Figure 10i,k,l). In addition, in the 2D wave spectra in Figure 11f (corresponding to 1D spectra in Figure 10k) shows a wide directional distribution similar to the observed 2D spectra (Figure 11c). This phenomenon is also shown in Figure 12e where the 1D spectra is uni-modal swell but the directional spectra indicates multi-directional wave energy. Type III bi-modal waves occur at LI (Figure 10b,e and Figure 11a,b) where the sea and swell energy peaks are close in frequency and from similar directions. Type I bi-modal waves occur early in the simulations, when the storm is further south and wave heights are small. Type IV bi-modal waves are not observed because none of the observation sites are in shallow water depths relative to the wave length.

\section{Summary and Conclusions}

Hurricane Sandy was a large storm with offshore waves up to $H_{s}=12.0 \mathrm{~m}$ in the open ocean. The storm made a westward turn, uncharacteristic of typical tropical cyclone tracks in the north Atlantic Ocean basin, and made landfall along a coastal region that is not typically struck by tropical cyclones. In this study three different 
spatially-varying surface wind fields are evaluated and compared to wind observations, including the parametric Holland (1980) model (H80), the parametric Generalized Asymmetric Holland Model (GAHM), and results from the WeatherFlow Regional Atmospheric Modelling System (WRAMS). The winds are used to drive the SWAN spectral wave model, and the wave statistics and directional wave spectra are compared to observations at offshore wave buoys to investigate the impact of differences between the complex wind fields on predictions of the sea surface evolution.

The wave simulations for three different spatially-varying wind fields for Hurricane Sandy revealed important differences in surface wave conditions. The WRAMS wind field produced wave model predictions with the highest agreement with wave observations, followed by the GAHM and H80, with mean correlation coefficients of $\bar{R}=0.91$, 0.82 and 0.75 and mean root-mean squared errors of RMSE $=1.33 \mathrm{~m}, 1.30 \mathrm{~m}$ and 2.44 m, respectively, averaged over 3.5 days at 9 sites. WRAMS and H80 tended to underpredict the bulk wave statistics while GAHM tended to over-predict the significant wave height, wave energy and water levels. The SWAN model results using WRAMS were used to classify the directional wave spectra for Hurricane Sandy, indicating that the model simulates bi-modal spectra in the two left quadrants of the hurricane in agreement with the observations. Closer to the hurricane centre, uni-modal spectra is observed and predicted, but a wide directional distribution in wave energy spectra suggests there are likely both sea and swell components in the spectra that have not had space to disperse. In the two right quadrants uni-modal spectra is observed and predicted.

The WRAMS wind field, developed from a 3D atmospheric model that assimilates meteorological observations, should be used to hindcast waves because it is the most representative of true hurricane wind and pressure conditions and produces the most accurate results in comparison to wave observations. The GAHM wind field, generated from a parametric vortex model that incorporates all available isotach information, 
should be used to forecast wave conditions from Best Track hurricane predictions. The H80 wind field, computed using a parametric vortex model that uses the wind speed only at the radius to maximum winds, produces a useful surface wind field that is simple to predict, but does not result in wave predictions in SWAN that are as accurate as using the GAHM winds. Although the focus of this research is on Hurricane Sandy, its meteorological characteristics were not unlike other tropical cyclones at midlatitudes that undergo extratropical transition or are influenced by other atmospheric disturbances making the results applicable to other hurricanes with large spatial size and high asymmetry. The results indicate that hurricane wind fields used to force ocean-scale wave models can accurately predict the spatial and temporal variability of surface waves needed to provide detailed boundary conditions to higher-resolution models for coastal regions.

\section{Acknowledgements}

We thank Marty Bell of WeatherFlow for sharing the WRAMS results, Rick Luettich of the University of North Carolina Institute of Marine Sciences for providing the GAHM model, Julia Hopkins of WHOI for modelling discussions, Maarten van Ormondt of Deltares for Delft3D advice, Cheryl Hapke and Tim Nelson of the US Geological Survey for helpful discussion on Hurricane Sandy, and two anonymous reviewers who provided insightful comments that helped improve the manuscript. The data used in this study is publicly available and the model results are archived at Queen's University. The research was funded by a Natural Sciences and Engineering Council of Canada (NSERC) Discovery Grant to the second author. 
Table 1: Observation sites used in this study

\begin{tabular}{ccccccc} 
Location & Acronym & Latitude & Longitude & Wind & Wave & Water level \\
\hline \hline New York Harbour & NYH & 40.369 & -73.703 & $\mathrm{x}$ & $\mathrm{x}$ \\
\hline Long Island & LI & 40.251 & -73.164 & $\mathrm{x}$ & $\mathrm{x}$ \\
\hline Block Island & BI & 40.969 & -71.127 & & $\mathrm{x}$ \\
\hline Cape Henry & CH & 36.915 & -75.720 & & $\mathrm{x}$ \\
\hline Delaware Bay & DB & 38.461 & -74.703 & $\mathrm{x}$ & $\mathrm{x}$ \\
\hline Nantucket & NT & 40.503 & -69.248 & $\mathrm{x}$ & $\mathrm{x}$ \\
\hline Virginia Beach & VB & 36.611 & -74.842 & & $\mathrm{x}$ \\
\hline East Hatteras & EH & 34.645 & -72.695 & & $\mathrm{x}$ \\
\hline Oregon Inlet & OI & 35.750 & -75.330 & & $\mathrm{x}$ \\
\hline Chesapeake Light & CL & 36.905 & -75.713 & $\mathrm{x}$ & \\
\hline Field Research Facility & FRF & 36.184 & -75.746 & $\mathrm{x}$ & \\
\hline \hline
\end{tabular}

Table 2: Statistics for significant wave height

\begin{tabular}{cccccc} 
Location & Model & $\mathrm{R}$ & RMSE $(\mathrm{m})$ & Bias $(\mathrm{m})$ & $\mathrm{SI}$ \\
\hline \hline New York Harbour & WRAMS & 0.96 & 1.10 & 0.92 & 0.03 \\
(NYH) & H80 & 0.80 & 2.02 & 1.55 & 0.07 \\
& GAHM & 0.82 & 1.35 & -0.43 & 0.04 \\
\hline Long Island & WRAMS & 0.96 & 1.19 & 1.04 & 0.03 \\
(LI) & H80 & 0.79 & 2.34 & 1.76 & 0.07 \\
& GAHM & 0.82 & 1.63 & -0.84 & 0.03 \\
\hline Block Island & WRAMS & 0.85 & 1.82 & 1.56 & 0.04 \\
(BI) & H80 & 0.52 & 2.66 & 1.61 & 0.06 \\
& GAHM & 0.96 & 0.70 & -0.48 & 0.01 \\
\hline Cape Henry & WRAMS & 0.98 & 0.51 & 0.45 & 0.01 \\
(CH) & H80 & 0.90 & 1.23 & 1.11 & 0.04 \\
& GAHM & 0.80 & 0.76 & -0.24 & 0.02 \\
\hline Delaware Bay & WRAMS & 0.96 & 1.15 & 1.02 & 0.04 \\
(DB) & H80 & 0.90 & 1.85 & 1.59 & 0.06 \\
& GAHM & 0.62 & 1.27 & -0.22 & 0.03 \\
\hline Nantucket & WRAMS & 0.78 & 2.15 & 1.76 & 0.06 \\
(NT) & H80 & 0.32 & 3.37 & 2.07 & 0.10 \\
& GAHM & 0.85 & 1.11 & 0.23 & 0.03 \\
\hline Virginia Beach & WRAMS & 0.94 & 1.06 & 0.73 & 0.03 \\
(VB) & H80 & 0.86 & 2.46 & 2.25 & 0.07 \\
& GAHM & 0.73 & 1.59 & -0.07 & 0.03 \\
\hline East Hatteras & WRAMS & 0.83 & 2.04 & 1.22 & 0.04 \\
(EH) & H80 & 0.82 & 3.80 & 3.38 & 0.09 \\
& GAHM & 0.88 & 2.17 & 0.68 & 0.04 \\
\hline Oregon Inlet & WRAMS & 0.95 & 1.26 & 1.03 & 0.03 \\
(OI) & H80 & 0.87 & 2.38 & 2.04 & 0.06 \\
& GAHM & 0.93 & 1.01 & 0.44 & 0.02 \\
\hline \hline Averaged over & WRAMS & 0.91 & 1.36 & 1.08 & 0.03 \\
all sites & H80 & 0.75 & 2.46 & 2.03 & 0.07 \\
& GAHM & 0.82 & 1.29 & -0.1 & 0.03 \\
\hline \hline & & & & &
\end{tabular}


Figure 1: Location map indicating the best track of Hurricane Sandy (thick black line) at 6-hr intervals (black circles) in the north Atlantic Ocean, with observation sites (see Table 1) indicated for waves (red dots), winds (red circles) and the location of the eye near Atlantic City (AC) at landfall (red triangle). This region corresponds to the numerical model domain with bathymetry in $m$ relative to mean sea level (colour contours), the $200 \mathrm{~m}$ depth contour (magenta line) and the coastline (thin black line).

Figure 2: Wind fields for Hurricane Sandy at Yearday 303.3 and 303.9 generated from: a)-b) the Holland (1980) model; c)-d) the Generalized Asymmetric Holland Model; and d)-e) the WeatherFlow Regional Atmospheric Modeling System. The best track (thick black line) at 6-hr intervals (black circles), wind magnitude (colour contours), wind direction (black vectors), and coastline (thin black line) are shown.

Figure 3: Time series of the atmospheric conditions $(U, V$ wind components and $P$ atmospheric pressure) generated by the H80 wind model (blue line), the GAHM wind model (green line), and the WRAMS wind model (red line) at six wind observation sites (black dots). Observation site locations are indicated in Figure 1.

Figure 4: Significant wave height predicted by SWAN for Hurricane Sandy at Yearday 303.3 and 303.9 generated using different wind field models: a)-b) the H80 wind model; c)-d) GAHM wind model; e)-f) WRAMS wind model. Wave direction (black arrows), significant wave height (colour contours), $H_{s}=10 \mathrm{~m}$ contour (red line) and coastline (thin black line) are shown.

Figure 5: Time series of predicted significant wave heights generated using the H80 wind model (blue line), the GAHM wind model (green line), and WRAMS wind model (red line) at nine wave observation (black line) sites.

Figure 6: Scatter plot of predicted significant wave heights compared to observations generated using H80 wind model (blue crosses,H), the GAHM wind model (green dots, G), and WRAMS wind model (red circles, W) at nine wave observation sites. Correlation coefficients $(\mathrm{R})$ for each model are listed in each plot.

Figure 7: Time series of predicted mean absolute wave periods generated using the H80 wind model (blue line), the GAHM wind model (green line), and WRAMS wind model (red line) at six wave observation (black line) sites. 
Figure 8: Time series of predicted peak wave directions generated using the H80 wind model (blue line), the GAHM wind model (green line), and WRAMS wind model (red line) at six wave observation (black line) sites.

Figure 9: Observations and simulations of wave spectral evolution for Hurricane Sandy using the WRAMS wind field at Long Island (LI) and Virginia Beach (VB) wave buoys. Energy contours at $10.5 \mathrm{~m}^{2} \mathrm{~Hz}^{-1}$ (black line) and selected time steps shown in Figure 10 (red lines) at Yearday 303.70, 303.90 and 303.95 are shown.

Figure 10: Wave energy spectra for Hurricane Sandy at Yearday t $1=303.70, \mathrm{t} 2=303.90$ and $\mathrm{t} 3=303.95$ generated using the H80 wind model (blue line), the GAHM wind model (green line), and the WRAMS wind model (red line) at four wave observation sites (black line).

Figure 11: Wave directional spectra plots for Hurricane Sandy at Yearday 303.7 from: a)-c) wave buoy observations d)-f) wave model predictions at three sites using the WRAMS wind forcing.

Figure 12: Predicted directional spectra during Hurricane Sandy generated by SWAN using the WRAMS wind field at Yearday 303.7; a) wind speed contours and wind direction vectors; b) significant wave height and wave direction vectors; with red circles that identify $1 \mathrm{D}$ and $2 \mathrm{D}$ wave spectra in each quadrant of the hurricane shown in $\mathrm{c})$-f). 


\section{References}

Amante C, Eakins B. ETOPO1 1 Arc-Minute Global Relief Model: Procedures, Data Sources and Analysis. 2009. doi:10.7289/V5C8276M.

Battjes J, Janssen J. Energy Loss and Set-Up due to Breaking of Random Waves. 1978. doi:10.9753/icce.v16.\{\\%\}p.

Bennett VC, Mulligan RP, Hapke C. A numerical model investigation of the impacts of Hurricane Sandy on Fire Island overwash and storm surge in Great South Bay, New York. Continental Shelf Research 2017;submitted.

Blake ES, Kimberlain TB, Berg RJ, Cangialosi JP, Ii JLB. Tropical Cyclone Report Hurricane Sandy. Technical Report October 2012; National Hurricane Center; 2013.

Booij N, Ris R, Holthuijsen L. A third-generation wave model for coastal regions 1. Model description and validation. Journal of Geophysical Research 1999;104(C4):7649-66. doi:10.1029/98JC02622.

Chen SS, Curcic M. Ocean surface waves in Hurricane Ike (2008) and Superstorm Sandy (2012): Coupled model predictions and observations. Ocean Modelling 2015;000:116. doi:10.1016/j.ocemod.2015.08.005.

Cotton W, Pielke Sr. R, Walko R, Liston G, Tremback C, Jiang H, McAnelly R, Harrington JY, Nicholls ME, Carrio GG, McFadden JP. RAMS 2001: Current status and future directions. Meteorology and Atmospheric Physics 2003;82(1-4):529. doi:10.1007/s00703-001-0584-9.

Dietrich J, Zijlema M, Westerink J, Holthuijsen L, Dawson C, Luettich R, Jensen R, Smith J, Stelling G, Stone G. Modeling hurricane waves and storm surge using integrally-coupled, scalable computations. Coastal Engineering 2011;58(1):45-65. doi:10.1016/j . coastaleng. 2010.08.001. 
Emanuel K. Increasing destructiveness of tropical cyclones over the past 30 years. Nature 2005;436(7051):686-8. doi:10.1038/nature03906.

Fan Y, Ginis I, Hara T, Wright CW, Walsh EJ. Numerical Simulations and Observations of Surface Wave Fields under an Extreme Tropical Cyclone. Journal of Physical Oceanography 2009;39(9):2097-116. doi:10.1175/2009JP04224.1.

Fan Y, Rogers WE. Drag coefficient comparisons between observed and model simulated directional wave spectra under hurricane conditions. Ocean Modelling 2016;102:1-13. doi:10.1016/j.ocemod.2016.04.004.

Federico S. Implementation of a 3D-Var system for atmospheric profiling data assimilation into the RAMS model: initial results. Atmospheric Measurement Techniques 2013;6(12):3563-76.

Gao J, Luettich R, Fleming J. Development and initial evaluation of a generalized asymmetric tropical cyclone vortex model in ADCIRC. ADCIRC users group meeting. US Army Corps of Engineers, Vicksburg 2013;.

Goldenberg SB, Landsea CW, Mestas-Nunez AM, Gray WM. The recent increase in Atlantic hurricane activity: causes and implications. Science (New York, NY) 2001;293(5529):474-9. doi:10.1126/science.1060040.

Hall TM, Sobel AH. On the impact angle of Hurricane Sandy's New Jersey landfall. Geophysical Research Letters 2013;40(10):2312-5. doi:10.1002/gr1.50395.

Halverson JB, Rabenhorst T. Hurricane Sandy: the science and impacts of a superstorm. Weatherwise 2013;66(2):14-23.

Hasselmann K, Barnett T, Bouws E, Carlson H, Cartwright D, Enke K, Ewing J, Gienapp H, Hasselmann D, Kruseman P, Meerburg A, Müller P, Olbers D, Richter K, Sell W, Walden H. Measurements of wind-wave growth and swell decay during the Joint North Sea Wave Project (JONSWAP). Technical Report; 1973. 
Hasselmann S, Hasselmann K, Allender J, Barnett T. Computations and parameterizations of the nonlinear energy transfer in a gravity-wave spectrum. Part II: Parameterizations of the nonlinear energy transfer for application in wave models. Journal of Physical Oceanography 1985;15(11):1378-91.

Holland GJ. An Analytic Model of the Wind and Pressure Profiles in Hurricanes. 1980. doi:10.1175/1520-0493(1980)108<1212: AAMOTW>2 . 0.CO;2.

Holthuijsen LH, Powell MD, Pietrzak JD. Wind and waves in extreme hurricanes. Journal of Geophysical Research: Oceans 2012;117(9):1-15. doi:10.1029/2012JC007983.

$\mathrm{Hu}$ K, Chen Q. Directional spectra of hurricane-generated waves in the Gulf of Mexico. Geophysical Research Letters 2011;38(19):1-7. doi:10.1029/2011GL049145.

Huang Y, Weisberg RH, Zheng L, Zijlema M. Gulf of Mexico hurricane wave simulations using SWAN: Bulk formula-based drag coefficient sensitivity for Hurricane Ike. Journal of Geophysical Research: Oceans 2013;118(8):3916-38. doi:10.1002/jgrc. 20283.

Jensen RE, Cialone A, Smith JM, Bryant MA, Hesser TJ. Regional Wave Modeling and Evaluation for the North Atlantic Coast Comprehensive Study. Journal of Waterway, Port, Coastal, and Ocean Engineering 2016;:B4016001doi:10.1061/(ASCE)WW .1943-5460.0000342.

Knutson TR, McBride JL, Chan J, Emanuel K, Holland G, Landsea C, Held I, Kossin JP, Srivastava AK, Sugi M. Tropical cyclones and climate change. Nature Geoscience 2010;3(3):157-63. doi:10.1038/ngeo779.

Landsea C, Franklin J, Blake E, Tanabe R. Northeast and North Central Pacific hurricane database (HURDAT2). Technical Report; National Hurricane Center (NHC) and the Central Pacific Hurricane Center (CPHC); 2016. 
Lesser G, Roelvink J, van Kester J, Stelling G. Development and validation of a three-dimensional morphological model. Coastal Engineering 2004;51(8-9):883-915. doi:10.1016/j.coastaleng. 2004.07.014

Mori N. Freak waves under typhoon conditions. Journal of Geophysical Research: Oceans 2012;117(C11).

Mulligan RP, Walsh JP, Wadman HM. Storm Surge and Surface Waves in a Shallow Lagoonal Estuary during the Crossing of a Hurricane. Journal of Waterway, Port, Coastal, and Ocean Engineering 2015;141(4):A5014001. doi:10.1061/(ASCE)WW. 1943-5460.0000260.

National Oceanic and Atmospheric Organization . National Buoy Data Center. 2016. URL: http://www.ndbc.noaa.gov/.

Pielke R, Cotton W, Walko R, Tremback C, Lyons W, Grasso L, Nicholls M, Moran M, Wesley D, Lee T, Copeland J. A comprehensive meteorological modeling system-RAMS. Meteorology and Atmospheric Physics 1992;49(1-4):69-91. doi:10.1007/BF01025401.

Sebastian A, Proft J, Dietrich JC, Du W, Bedient PB, Dawson CN. Characterizing hurricane storm surge behavior in Galveston Bay using the SWAN+ADCIRC model. Coastal Engineering 2014;88:171-81. doi:10.1016/j.coastaleng. 2014.03.002.

Tolman HL. User manual and system documentation of WAVEWATCH III TM version 3.14. Technical Report; NOAA / NWS / NCEP / MMAB Technical Note 276; 2009. U.S. National Weather Service . Environmental Modelling Center: WaveWatch III. 2016.

Wang H, Loftis J, Liu Z, Forrest D, Zhang J. The storm surge and sub-grid inundation modeling in New York City during Hurricane Sandy. Journal of Marine Science and Engineering 2014;2(1):226-46. doi:10.3390/jmse2010226. 
${ }_{561}$ WeatherFlow . Storm Coverage - Sandy 2012. 2016. URL:

562 http://ds.weatherflow.com/storm.

${ }_{563}$ van der Westhuysen AJ, Zijlema M, Battjes JA. Nonlinear saturation-based white-

${ }_{564}$ capping dissipation in SWAN for deep and shallow water. Coastal Engineering

${ }_{565} \quad 2007 ; 54(2): 151-70$. doi:10.1016/j.coastaleng.2006.08.006.

${ }_{566}$ Young I. Directional spectra of hurricane wind waves. Journal of Geophysical Research 567 2006;111(C08020):1-14. doi:10.1029/2006JC003540.

${ }_{568}$ Zijlema M. Computation of wind-wave spectra in coastal waters with ${ }_{569}$ SWAN on unstructured grids. Coastal Engineering 2010;57(3):267-77. ${ }_{570}$ doi:10.1016/j.coastaleng. 2009.10.011. 


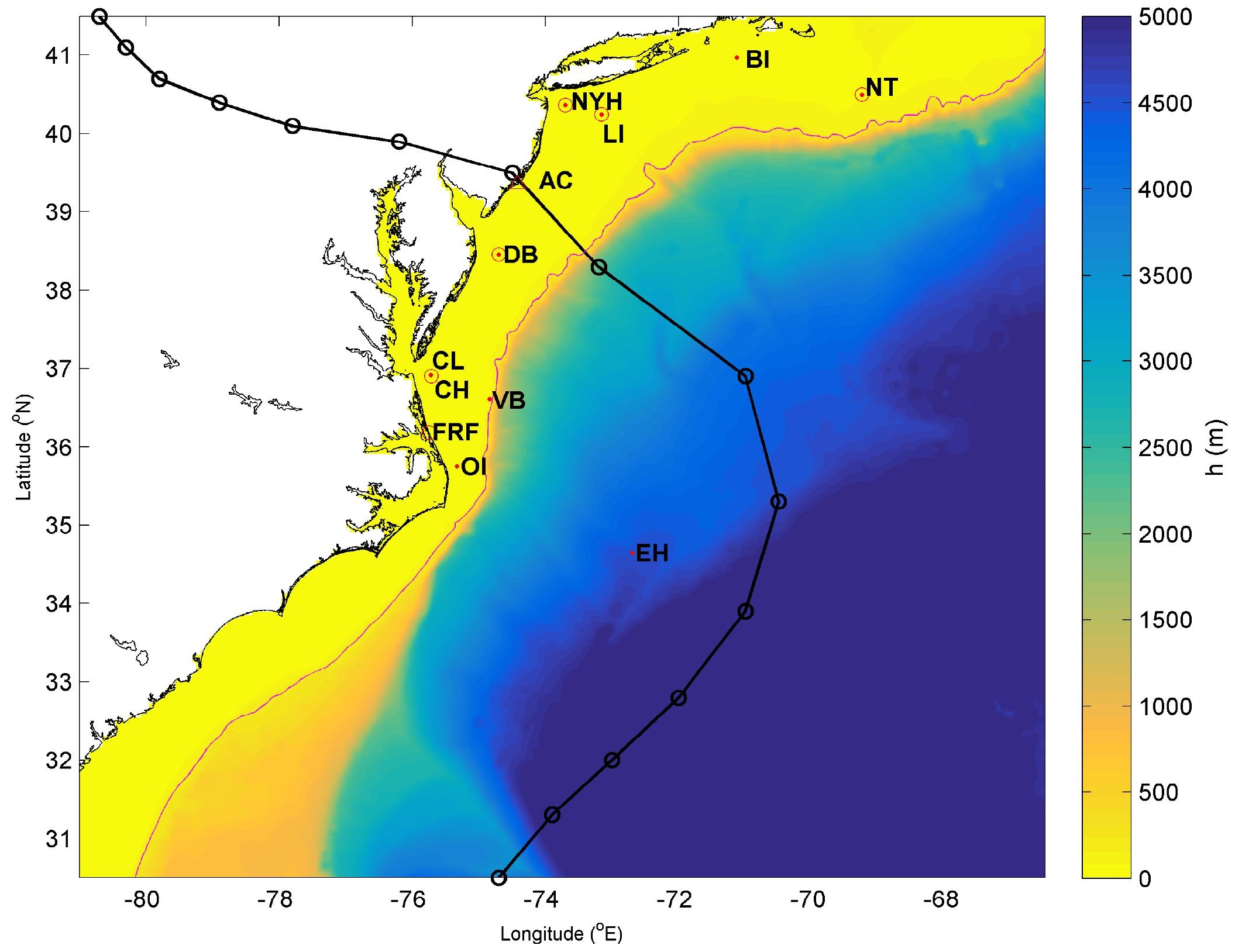



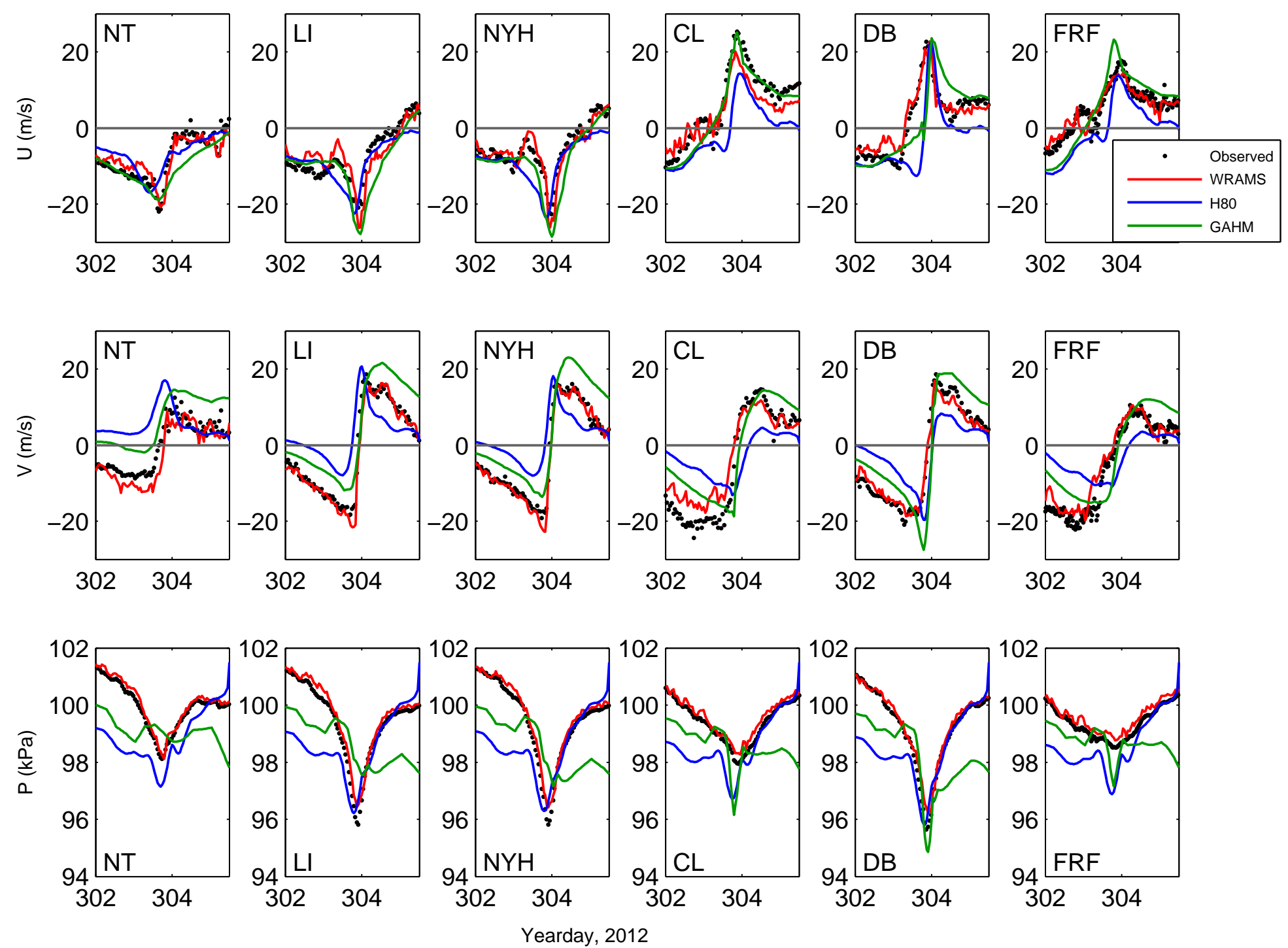
a) H80: Yearday 303.3

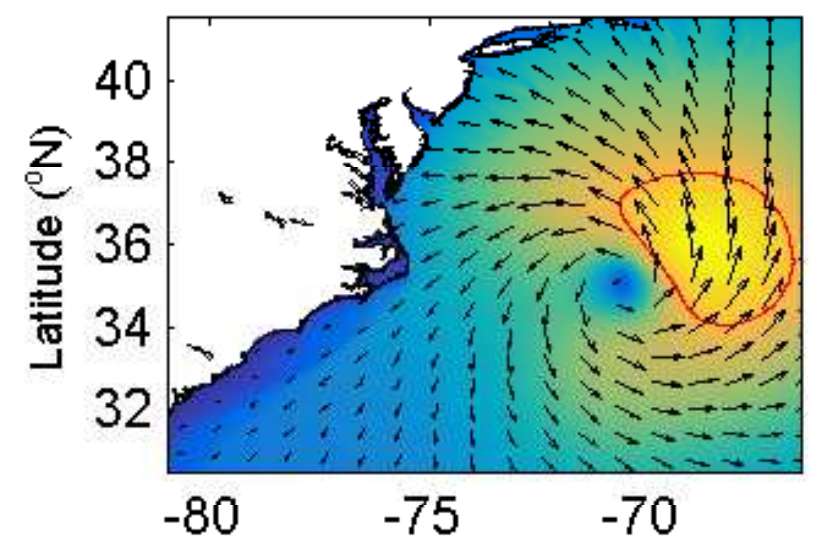

c) GAHM: Yearday 303.3

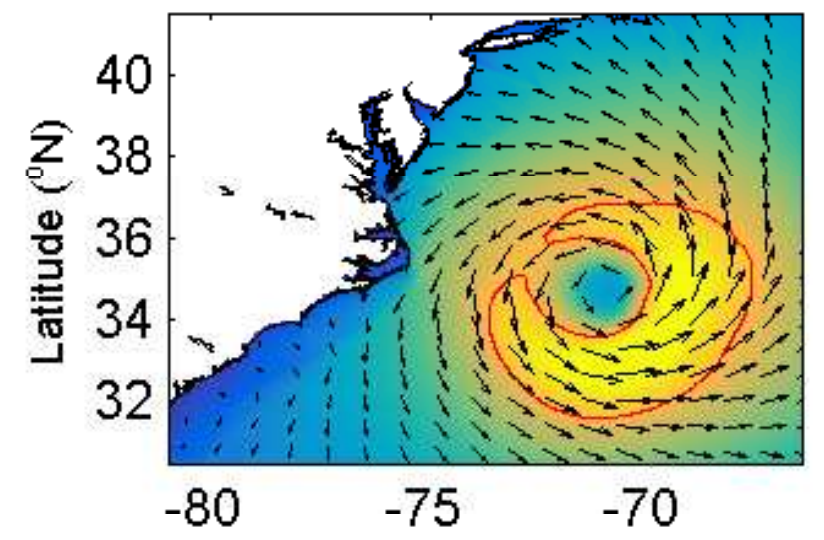

e) WRAMS: Yearday $\mathbf{3 0 3 . 3}$

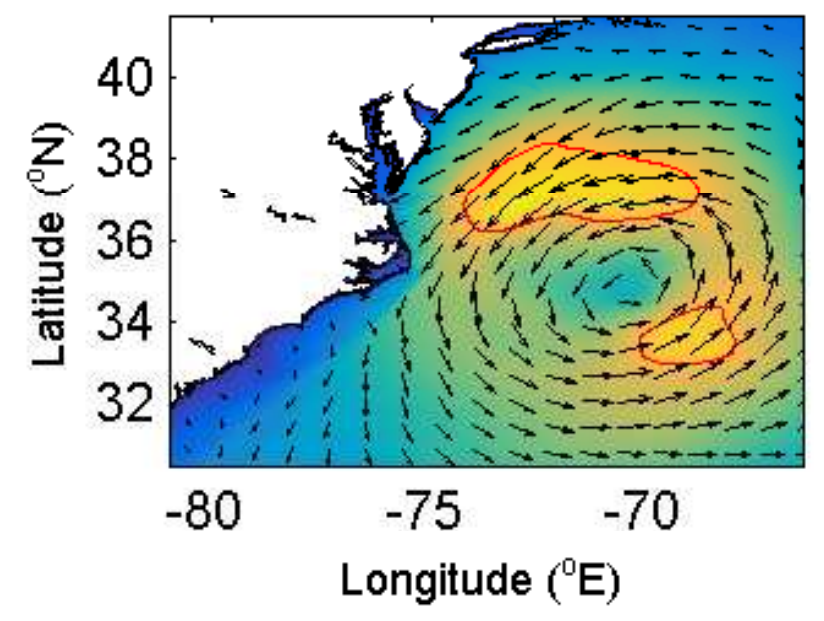

b) H80: Yearday 303.9
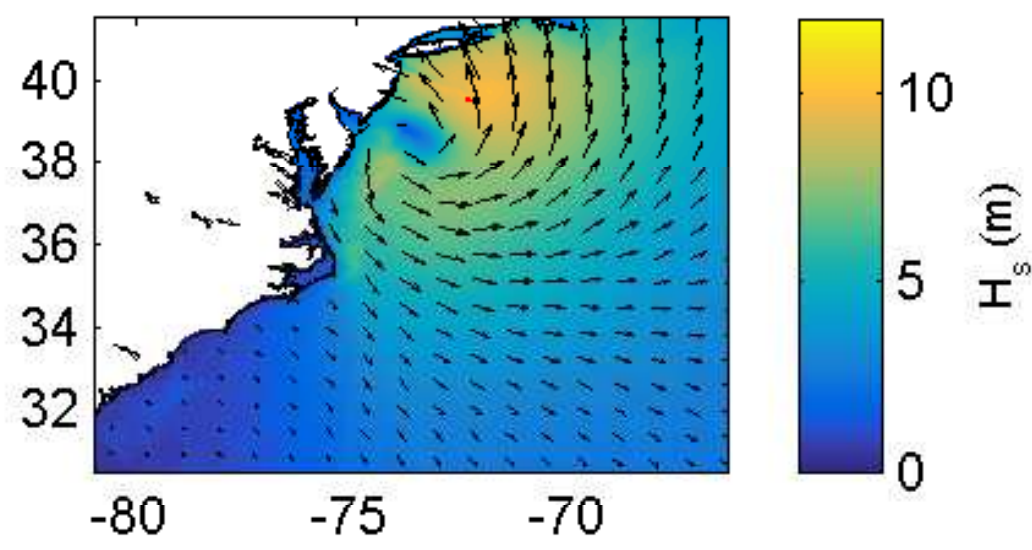

d) GAHM: Yearday $\mathbf{3 0 3 . 9}$

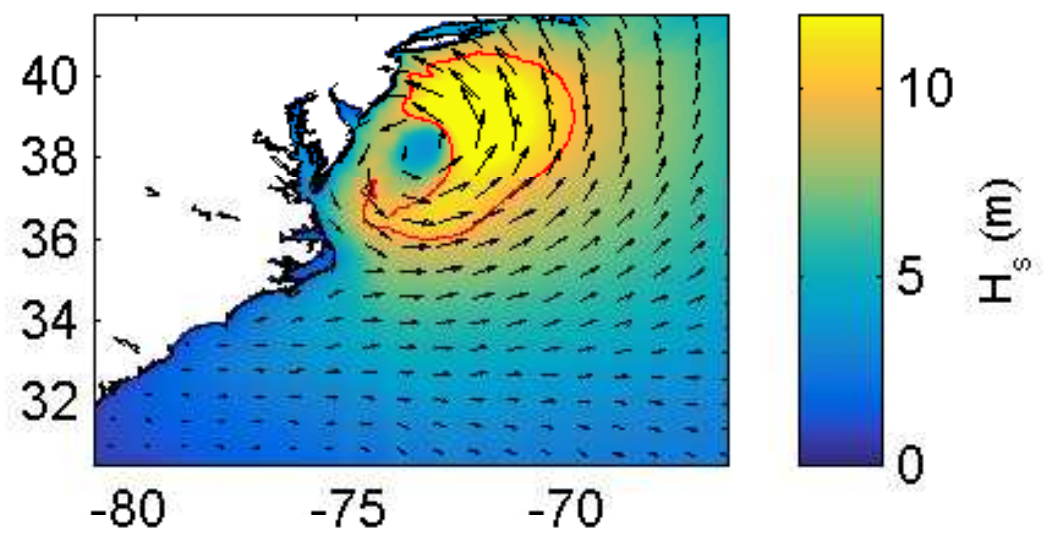

f) WRAMS: Yearday 303.9

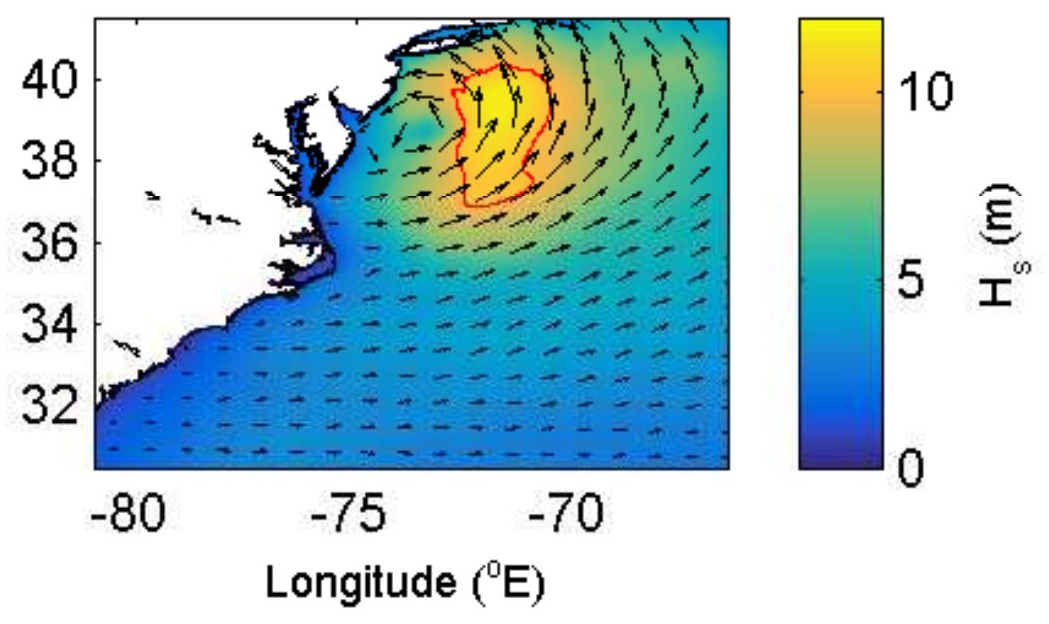



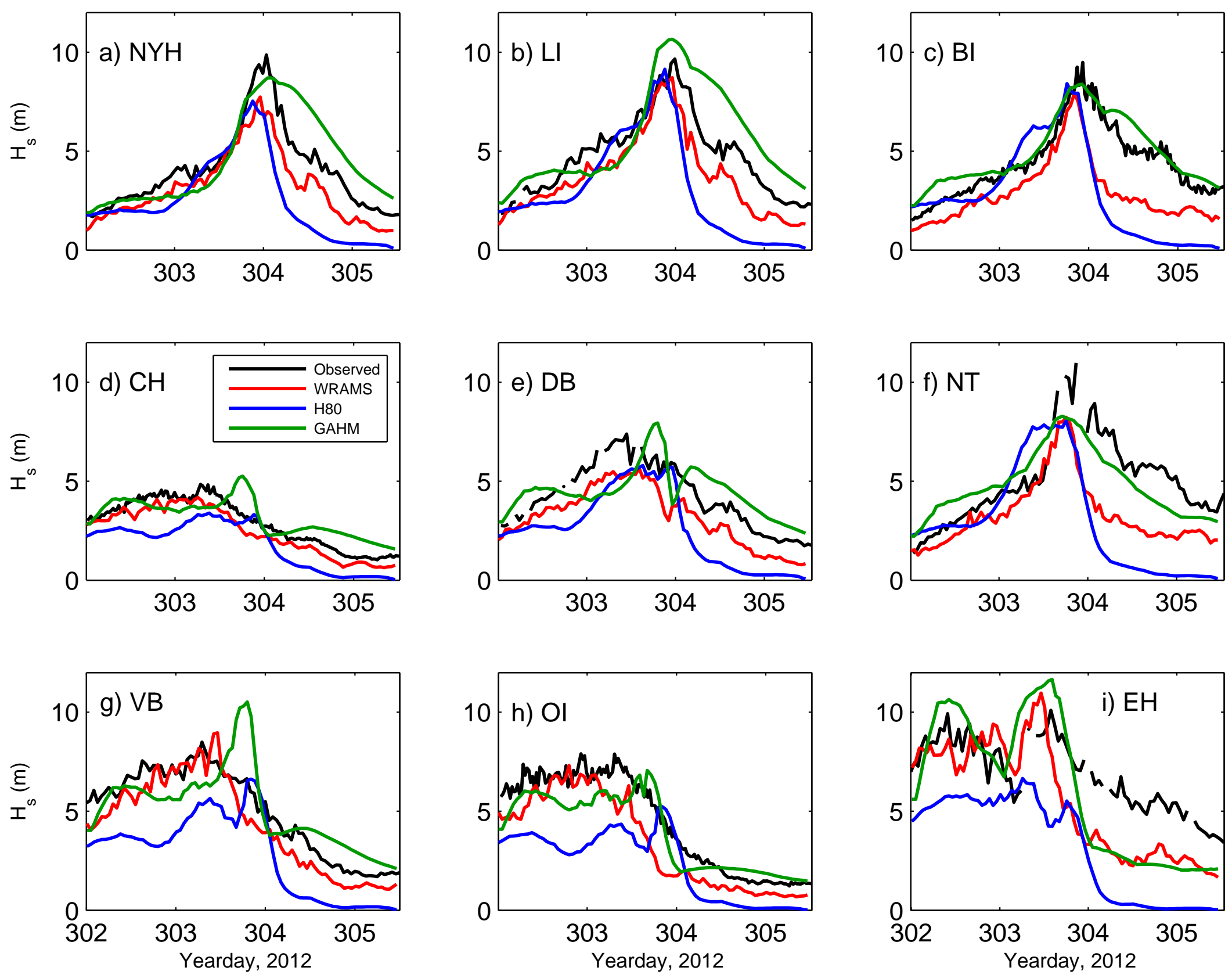

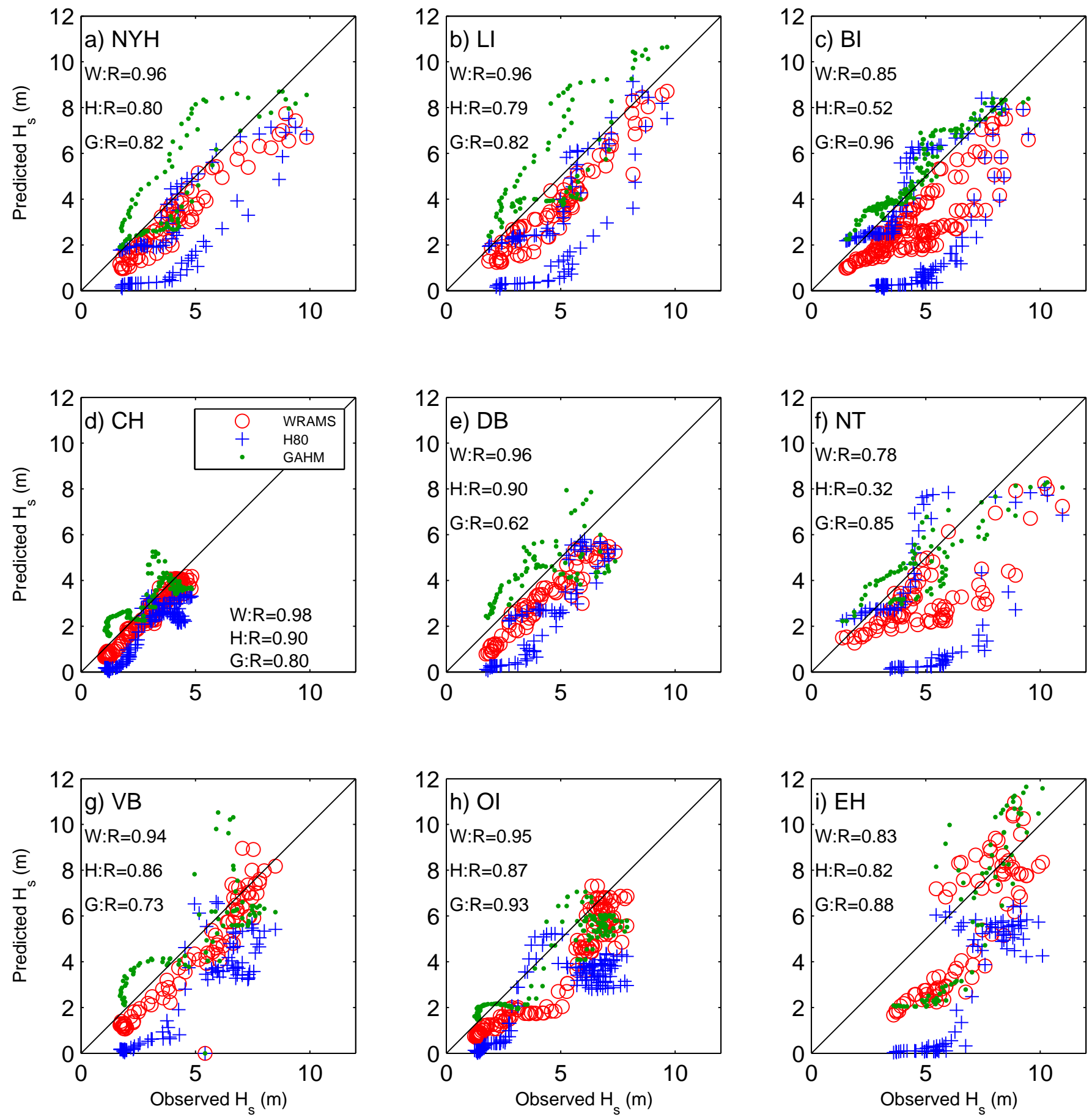

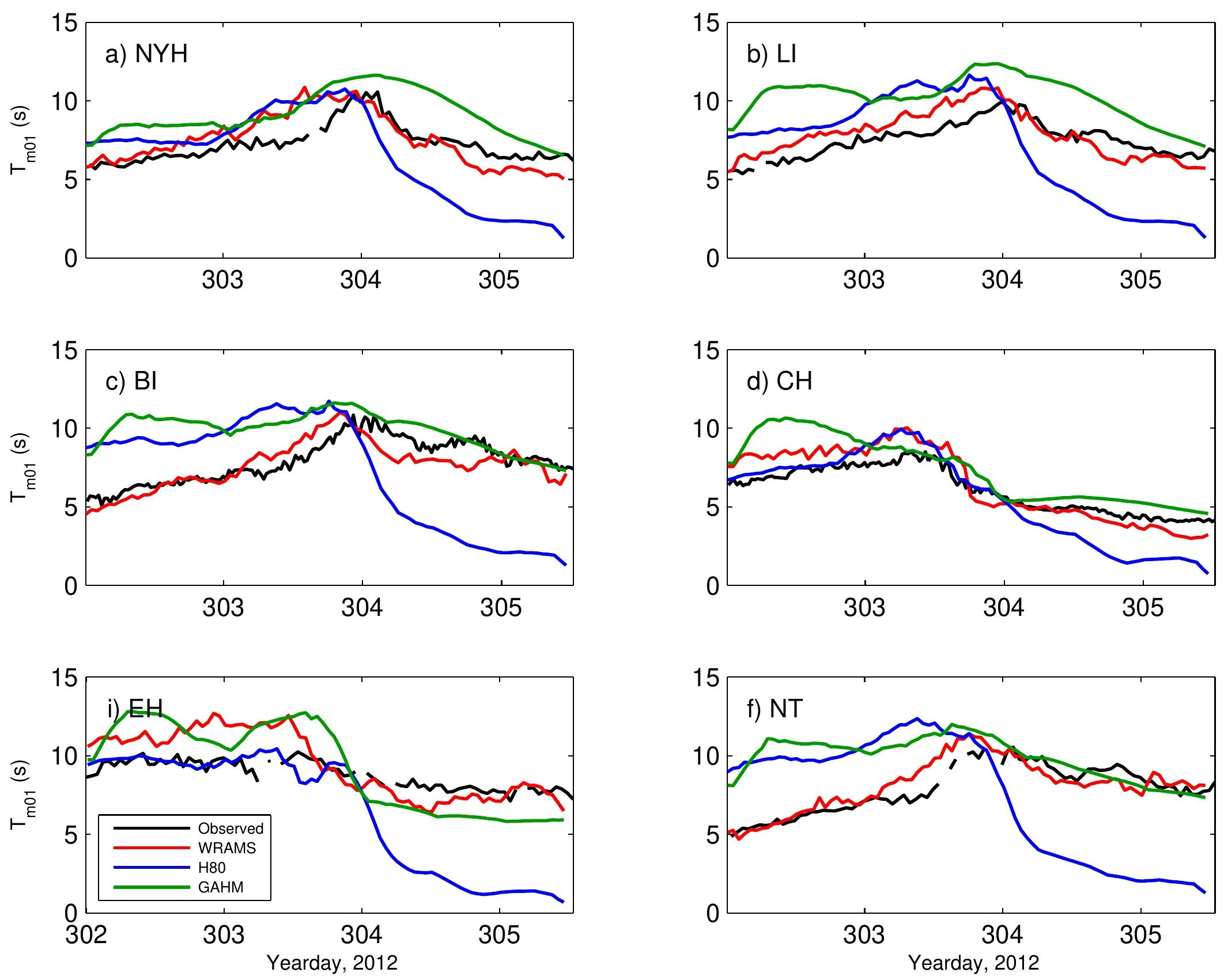

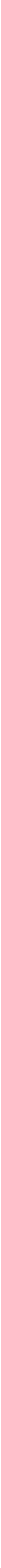

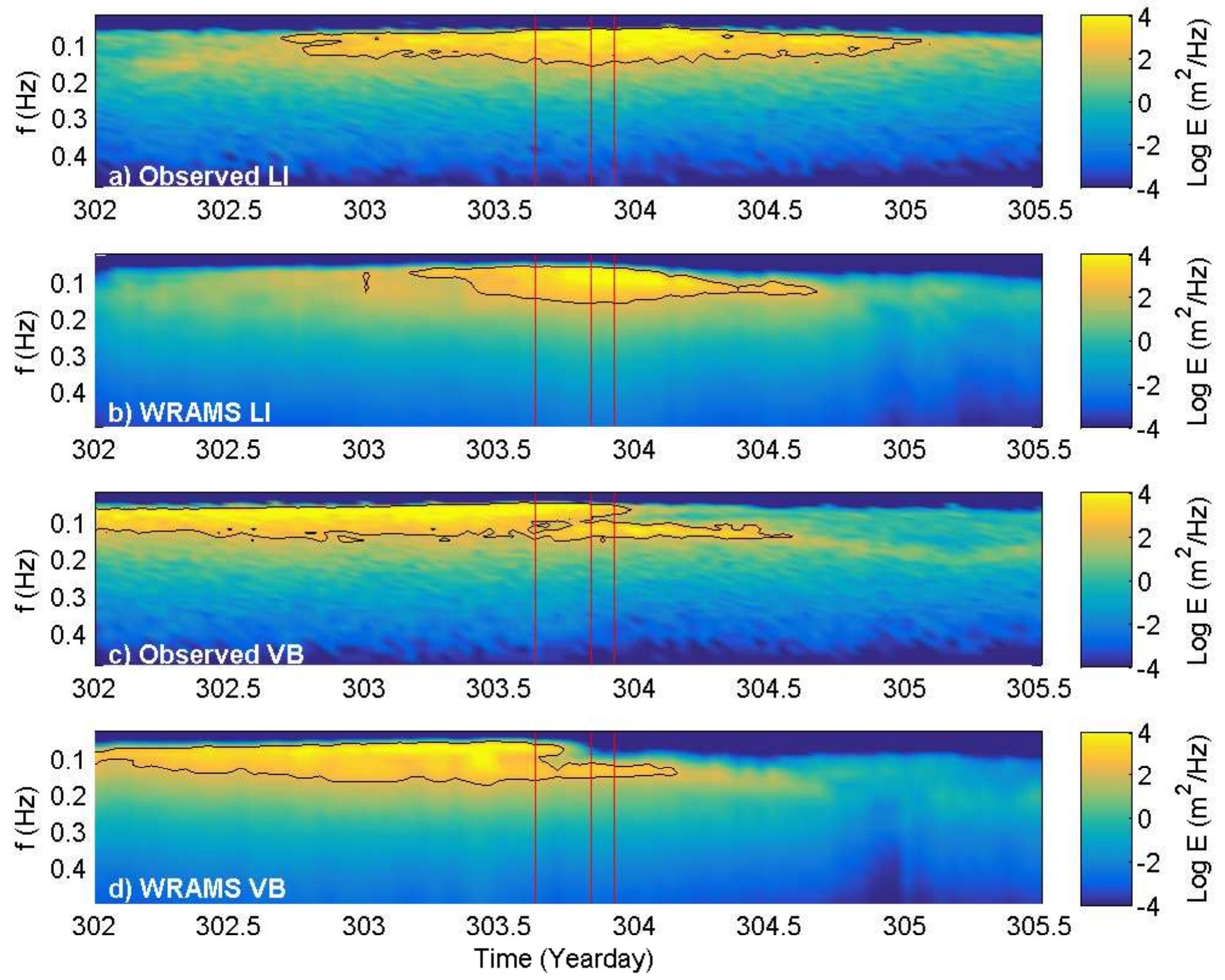

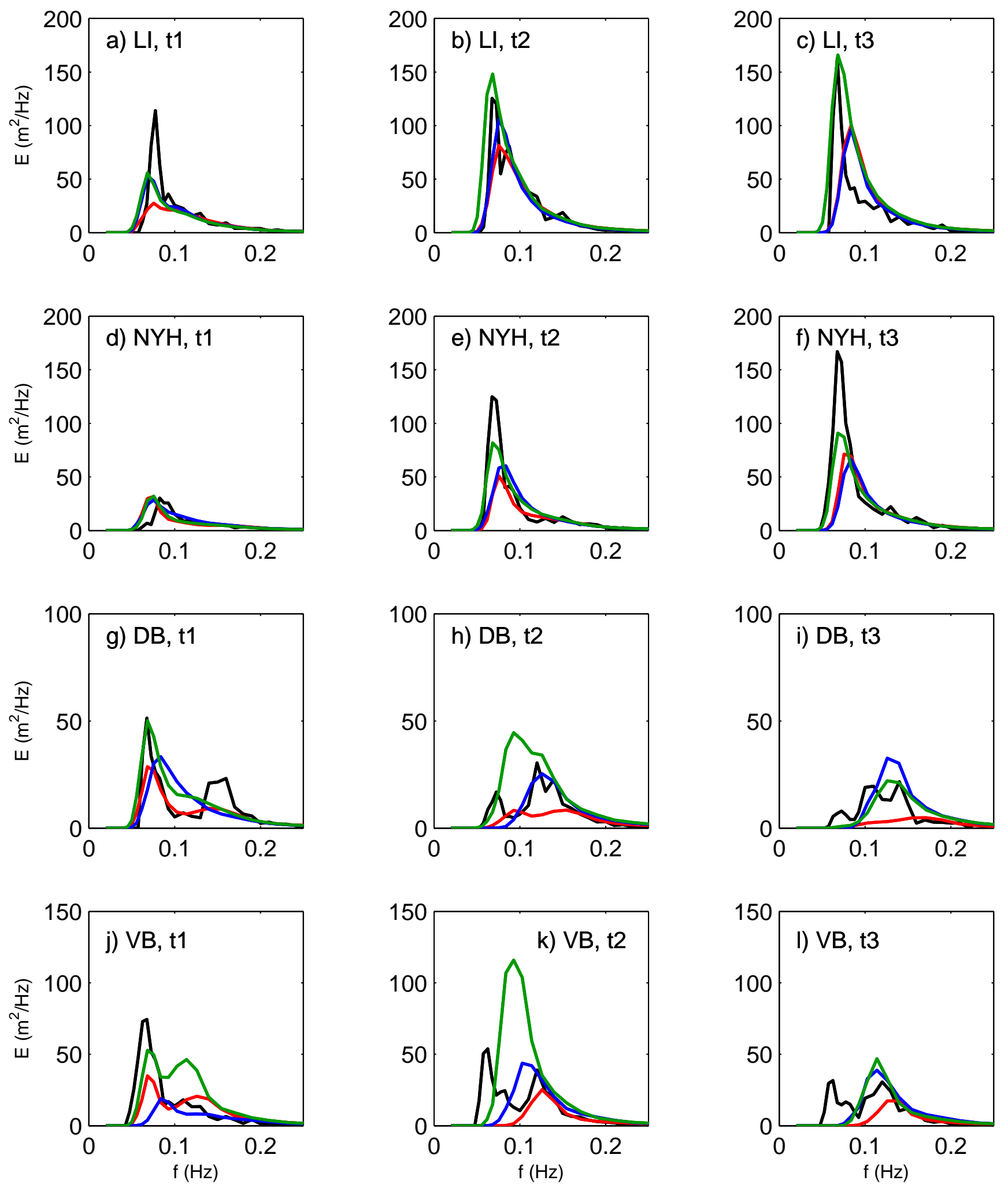
a) Observed LI

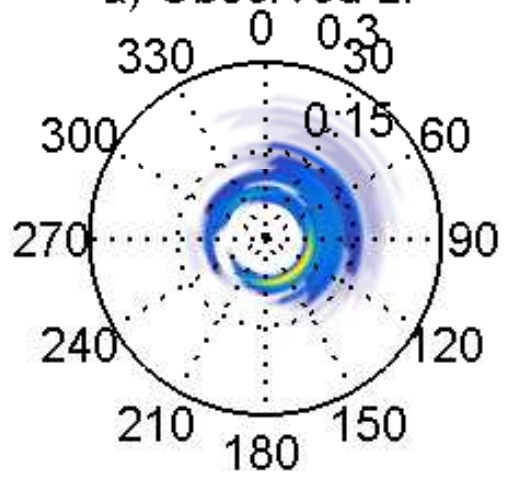

b) Observed NYH

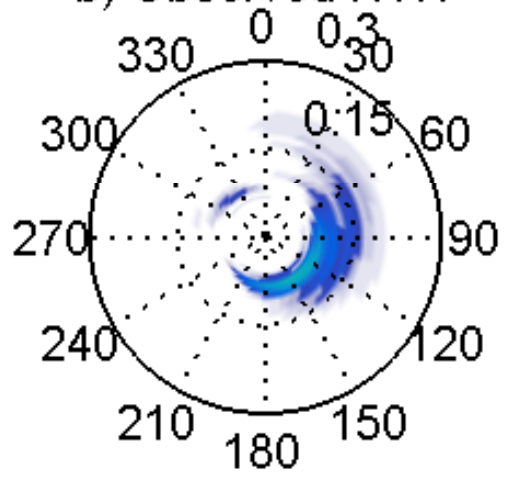

c) Observed VB

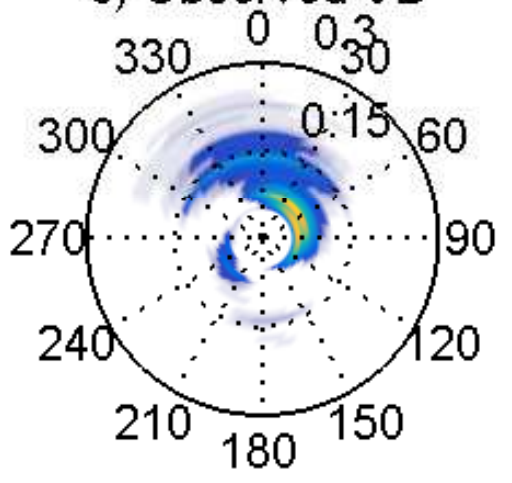

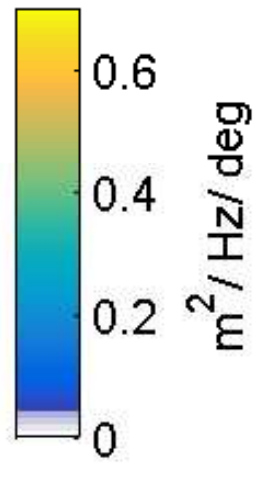
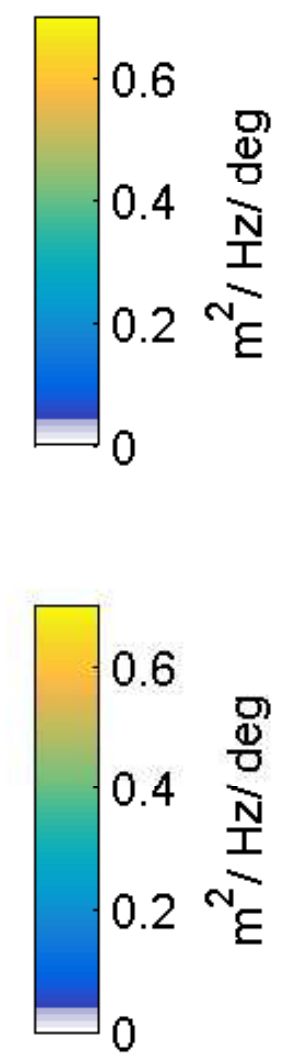

d) WRAMS LI
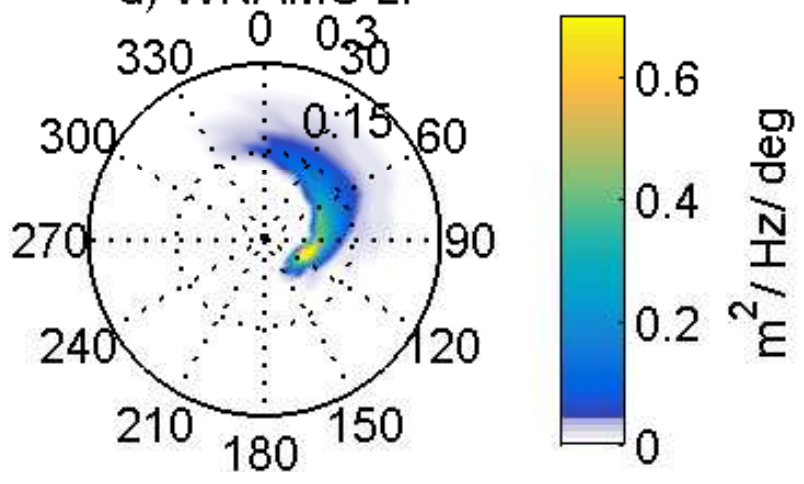

e) WRAMS NYH
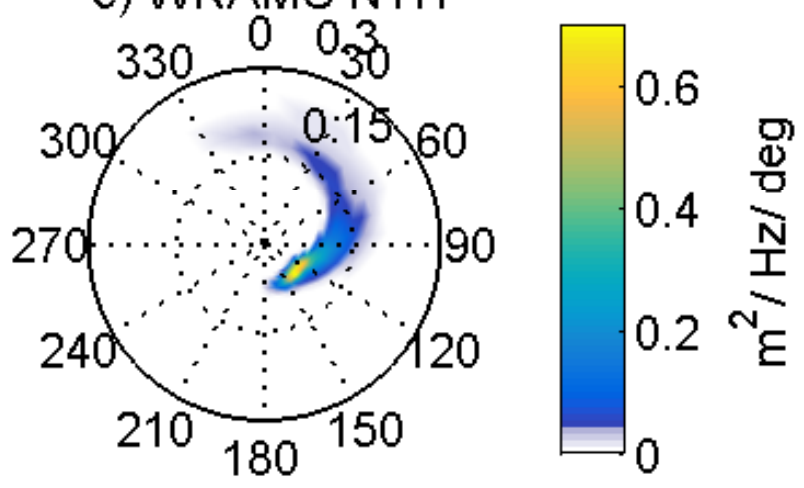

f) WRAMS VB

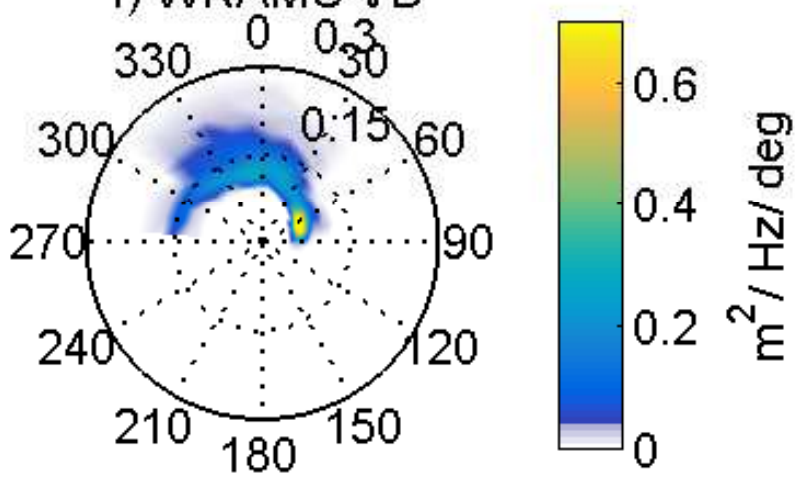



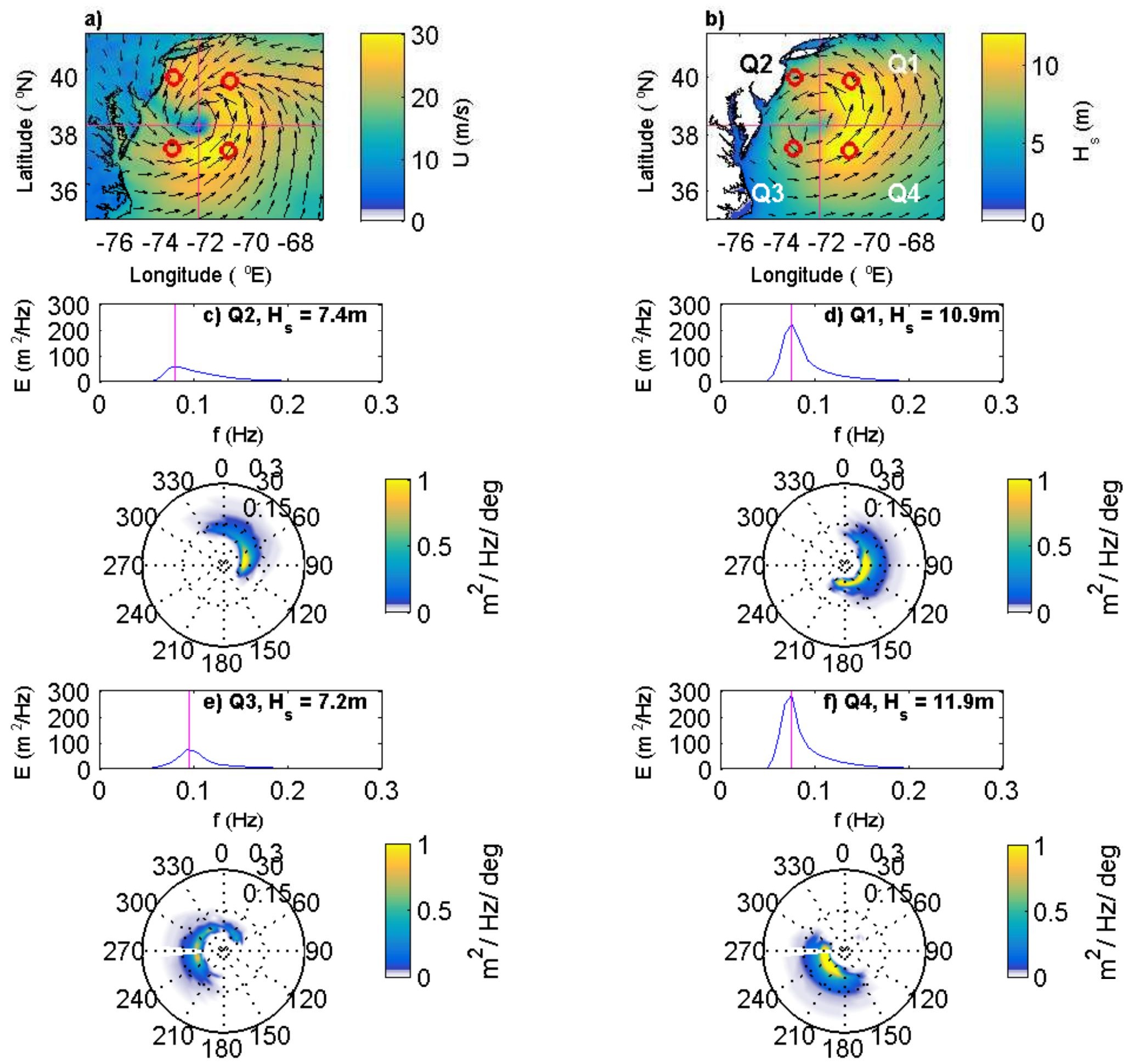